Article

\title{
Effect of Corrosion Characteristics on Long-Term Aging of Austenitic 304 Steel
}

\author{
Chaeeul Huh, Seongbin An, Minsuk Kim and Chungseok Kim * (it \\ Department of Materials Science and Engineering, Chosun University, Gwangju 501759, Korea; \\ gjcodmf@naver.com (C.H.); tjdqls1134@naver.com (S.A.); okms1304@naver.com (M.K.) \\ * Correspondence: chs2865@chosun.ac.kr; Tel.: +82-62-230-7197
}

Received: 15 November 2019; Accepted: 13 December 2019; Published: 17 December 2019

\begin{abstract}
The objective of this study is to investigate the effect of long-term aging on electrochemical corrosion characteristics of austenitic AISI 304 steel. AISI 304 steel was subjected to aging treatment for an extended period at $700{ }^{\circ} \mathrm{C}$ up to a maximum of $10,000 \mathrm{~h}$. The variation in the microstructure of aged specimens was observed with an optical microscope (OM) and a scanning electron microscope (SEM). The electrochemical polarization test was conducted to obtain the corrosion current density (Icorr) and corrosion potential (Ecorr). The metastable intermetallic $\mathrm{M}_{23} \mathrm{C}_{6}$ carbides generated in the vicinity of $\gamma / \gamma$ grain boundaries and coarsened with aging time. The $\delta$-ferrite island decomposed into $\sigma$-phase and $\mathrm{M}_{23} \mathrm{C}_{6}$ carbide with an aging time increase. As the aging time increased, the current density increased, but the corrosion potential of the austenitized specimen exhibited a minimum value of $0.04 \mu \mathrm{A} / \mathrm{cm}^{2}$. The highest pitting resistance exhibited at the austenitized specimen due to the absence of carbides. Consequently, the corrosion resistance of austenitic AISI 304 steel decreases with long-term aging time. The microstructural analyses well support this result.
\end{abstract}

Keywords: AISI 304; long-term aging; corrosion; sensitization; delta ferrite

\section{Introduction}

Austenitic stainless steels are chrome-nickel alloy steels with excellent corrosion resistance, high strength, and good weldability. This excellent corrosion resistance is due to the chromium content higher than $16 \%$ that forms an oxide protective film on the surface. Therefore, they are widely used as essential materials for vessels and pipes in power plants, chemical industries, medical applications, and structural facilities. Even though these austenitic structural materials have excellent mechanical properties and corrosion resistance, they become deteriorated and degraded due to high temperature, high pressure, and long-term use [1-3]. Although many previous studies have reported material degradation, there is a lack of reporting of long-term material degradation for 10,000 $\mathrm{h}$ and at high temperatures of $700{ }^{\circ} \mathrm{C}$ in austenitic steel $[4,5]$.

When the austenitic stainless steel is exposed to temperatures between 600 and $800{ }^{\circ} \mathrm{C}$, it is susceptible to sensitization. During sensitization, the $\mathrm{Cr}$-rich carbides generated along grain boundaries and twin boundaries, which caused depletion of $\mathrm{Cr}$ atoms in the vicinity of grain boundaries. In most studies, the mechanism of sensitization of stainless steel is about $\mathrm{Cr}$ depletion due to the generation of metastable intermetallic precipitation, which makes the $\mathrm{Cr}$ amount at the grain boundary fall below $12 \%$ [6]. Tekin et al. studied the grain boundary sensitization and desensitization during the aging of AISI 316 austenitic stainless steel at temperatures between 550 and $750{ }^{\circ} \mathrm{C}$. They reported that the $\mathrm{Cr}$ contents dropped below $13 \%$ and more due to the $\mathrm{Cr}$ depletion at grain boundary [7]. Rhouma et al. studied the intergranular corrosion behavior of AISI 316 stainless steel aged in the range between 550 and $700{ }^{\circ} \mathrm{C}$. They measured the $\mathrm{Cr}$ concentration at the vicinity of grain boundary during aging at each temperature. They also reported that the $\mathrm{Cr}$ concentration decreased below $12 \%$ at grain boundary [8]. 
The $\delta$-ferrite, which is the body centered cubic (BCC) crystal structure, is formed during solidification and remains along grain boundaries at room temperature in stainless steel. It successfully acts as a strong barrier to the dislocation motion, slows grain growth, and enhances mechanical strength because the interphase boundaries act as strong barriers to the dislocation motion [9]. In addition, this $\delta$-ferrite can transform into the $\sigma$-phase in the austenite through heat treatment, in which the $\sigma$-phase is an intermetallic compound with a tetragonal crystal structure. The chemical composition of this $\sigma$-phase varies considerably. Therefore, it is difficult to define this phase in the form of unique formulas. The precipitation rate of the $\sigma$-phase from the $\delta$-ferrite is about 100 times more rapid than directly from austenite due to the $\mathrm{Cr}$ content and diffusion [10]. The $\sigma$-phase has a negative effect on the mechanical properties, such as toughness and ductility because it is hard, brittle and nonmagnetic. In general, the presence of the $\delta$-ferrite decreases the incubation period of the generation of the $\sigma$-phase. Therefore, the small fraction of $\delta$-ferrite, less than $1 \%$, has been recommended in order to avoid hot cracking and brittle $\sigma$-phase resulting from the welding of austenitic stainless steel. It is therefore of considerable importance to identify the decomposition of ferrite and austenite during the long-term aging process and to quantify the associated chromium depletion in order to understand their specific effects on the corrosion behavior. In fact, the effect of $\sigma$-phase and $\delta$-ferrite on corrosion resistance is not clear and is not studied enough.

The objective of this study is to investigate the influence of long-term aging on electrochemical corrosion characteristics of AISI 304 steel. AISI 304 steel was subjected to aging treatment for a long time up to a maximum of $10,000 \mathrm{~h}$ at a temperature of $700{ }^{\circ} \mathrm{C}$.

\section{Experimental Details}

The test materials are austenitic AISI 304 stainless steel. The composition of the test specimens is shown in Table 1. It was analyzed by the inductively coupled plasma mass spectrometry (ICP-MS). In order to observe the microstructure of the aging specimens for a long time, the specimens were prepared by cutting them into $10 \mathrm{~mm} \times 10 \mathrm{~mm}$ in size from the aging specimens and mounting them at low temperature using a mounting resin. The observation surface was polished using alumina paste of $1 \mu \mathrm{m}$ in turn after mechanical polishing from \#220 to \#2000. The surface was corroded by chemical etching, and the corrosion solution was immersed in Vilella's reagent (Glycerol $45 \mathrm{~mL}+$ Nitric acid $15 \mathrm{~mL}+$ Hydrochloric acid $30 \mathrm{~mL}$ ) solution at room temperature for about $1 \mathrm{~min}$, corroded, and washed clean. The microstructural variation of long-term aging samples was observed by optical microscope (OM, Cal Zeiss: Axio Vert. A1, GER) and scanning electron microscope (SEM, Seron: AIS 2000C, KOR).

Table 1. Chemical composition of AISI 304 stainless steel (wt \%).

\begin{tabular}{cccccccccc}
\hline $\mathbf{C}$ & $\mathbf{S i}$ & $\mathbf{M n}$ & $\mathbf{P}$ & $\mathbf{S}$ & $\mathbf{M o}$ & $\mathbf{N i}$ & $\mathbf{C r}$ & $\mathbf{C u}$ & $\mathbf{F e}$ \\
\hline 0.038 & 0.62 & 1.48 & 0.014 & 0.025 & 0.40 & 8.68 & 18.27 & 0.60 & $\mathrm{Bal}$ \\
\hline
\end{tabular}

In order to perform precise surface element analysis, an electron probe microanalyzer (EPMA, Jeol: JXA-8230, JAP) was used. Elemental analysis was performed with an acceleration voltage of $15 \mathrm{kV}$, a beam current of $20 \mathrm{nA}$, and a beam size of $1 \mu \mathrm{m}$.

As shown in Figure 1, the test specimens were subjected to austenitizing treatment at $1200{ }^{\circ} \mathrm{C}$ for $6 \mathrm{~h}$ and water quenching, followed by artificial aging at $700{ }^{\circ} \mathrm{C}$ for a determined time. The interrupt test was conducted to fabricate the test samples with different aging time, such as 100, 1000, 5000, and $10,000 \mathrm{~h}$, respectively.

The austenitic AISI 304 steel is typical stainless steel and has a face-centered cubic (FCC) structure. In general, $\delta$-ferrite formed during the casting process is present at grain boundaries. $X$-ray diffraction analysis was performed to identify the crystal structures. Scan intervals from 30 degrees to 100 degrees using an X-ray diffractometer (XRD, Rigaku; X'pert PRO MPD, JAP) were performed in a $2 \theta$ scan with 
0.01 degrees and holding time of $1 \mathrm{~s}$. X-rays were set to a current of $30 \mathrm{~mA}$ and a tube voltage of $40 \mathrm{kV}$ under CuKa $(\lambda=1.54060)$ target conditions.

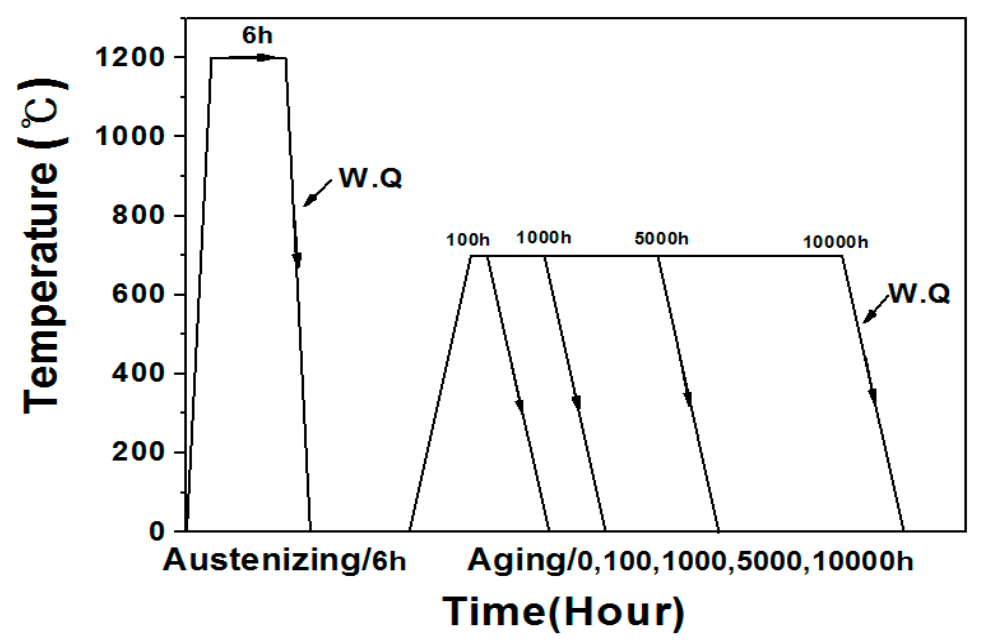

Figure 1. Heat treatment history of AISI 304 stainless steel.

A ferrite scope was used to measure the fraction of $\delta$-ferrite presented at the austenite grain boundaries. Ferrite scopes are measured according to the magnetic induction method. The magnetic field generated by the coil interacts with the magnetic component of the test specimen, and the change in the magnetic field causes a voltage change proportional to the ferrite component in the secondary coil. This voltage is evaluated to determine the ferrite component [11]. Ten times were measured for each test piece using this ferrite scope (Fischer; Mp-30E, AUS). For the purpose of magnetic force microscopy observation, the size of the specimen was prepared by machining $10 \mathrm{~mm} \times 10 \mathrm{~mm} \times 5 \mathrm{~mm}$. The surface was ground for $4 \mathrm{~h}$ using a vibratory polishing machine.

The electrochemical corrosion test was employed in a standard three-electrode system (WonATech; ZIVE SP 1, KOR). The working electrode at which the AISI 304 specimen was exposed with $1 \mathrm{~cm}^{2}$ area. A saturated calomel electrode was used for a reference electrode, and a platinum wire electrode was also used for the auxiliary electrode. All corrosion test was achieved in a $0.75 \% \mathrm{NaCl}$ solution at room temperature. The experiment was carried out using the SM6 program, and the potential range was specified from $-0.5 \mathrm{~V}_{\text {sce }}$ to $1.5 \mathrm{~V}_{\text {sce }}$ and was open-circuit. The scan rate was $1 \mathrm{mV} / \mathrm{s}$, and the current (I) range was $10 \mathrm{~mA}$, and the experiment time was about $30 \mathrm{~min}$.

\section{Results and Discussion}

\subsection{Microstructure Analysis}

Figure 2 depicts the OM photographs of the surface microstructure at each aging treated sample. As shown in Figure 2a, the initial aging state of the austenitized sample showed that the grains had polygonal shape and the typical annealing twins were observed in most grains. Song et al. reported that annealing twins exist inside the austenite grains in equiaxed grains [11]. Most of all, the grain boundaries are not clear due to no precipitation along the grain boundary. Figure $2 b$ is an optical micrograph after $100 \mathrm{~h}$ of heat treatment, and the grain boundaries start to appear clearly, and the $\delta$-ferrite appears as a dark island on the $\gamma / \gamma$ interface of the grain boundary. Figure $2 \mathrm{c}$ is a micrograph of $1000 \mathrm{~h}$ heat treatment sample, the grain boundary becomes clearer due to precipitation along the grain boundary, and the grain shape starts to change into a round shape. Figure $2 \mathrm{~d}$ is a micrograph of $5000 \mathrm{~h}$ of heat treatment sample. In addition to the grain boundary, the precipitates can be observed within the grain interior after $5000 \mathrm{~h}$ of heat treatment, and this phenomenon is more prominent at 10,000 $\mathrm{h}$ heat treatment sample as shown in Figure 2e. As the heat treatment time increased, many precipitates were formed along with $\gamma / \gamma$ interface of the grain boundary and also within a grain interior. 

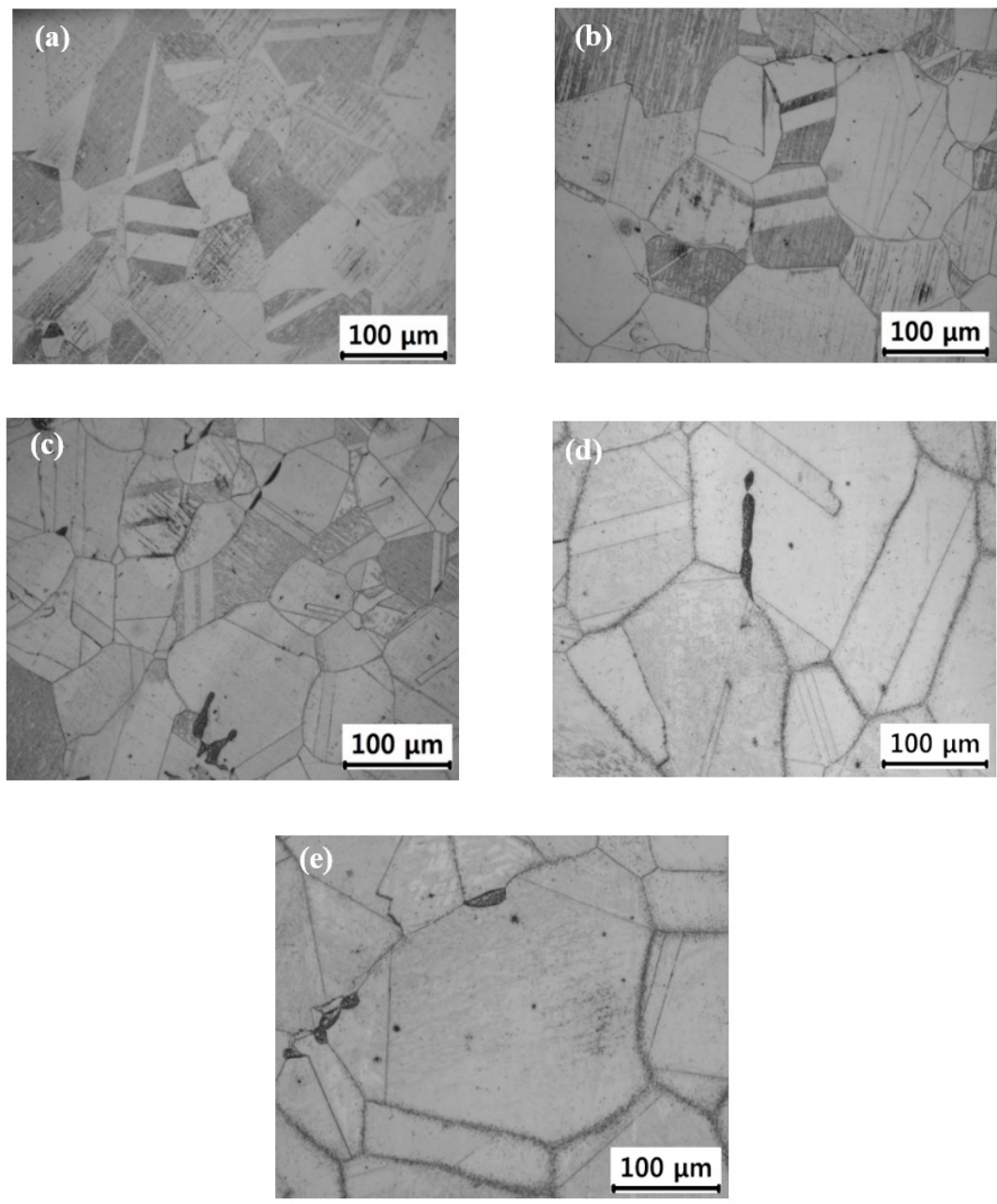

Figure 2. Optical micrographs of long-term material degradation; (a) 0 h, (b) $100 \mathrm{~h}$ (c) $1000 \mathrm{~h}$, (d) $5000 \mathrm{~h}$, and (e) $10,000 \mathrm{~h}$.

Figure 3 shows the micrographs of grain boundaries observed by the SEM. In the initial state of the austenitized sample, no precipitates were observed along the grain boundary as already mentioned in Figure 2. However, as the heat treatment time increased, the precipitates generated and coarsened along the grain boundaries, which are known as Cr-rich intermetallic carbides [12]. For $100 \mathrm{~h}$ aging sample, the most intermetallic carbides $\mathrm{M}_{23} \mathrm{C}_{6}$ generated along grain boundaries. However, in addition to the grain boundary, the precipitation also starts to generate within the grain interior as shown in Figure 3c. This precipitation within the grain interior is dominant after $5000 \mathrm{~h}$ of aging time. Figure 4 shows the SEM micrographs of $\delta$-ferrite phase along the grain boundary. It can be seen that the decomposition of $\delta$-ferrite proceeds rapidly with increasing aging time, and the $\delta$-ferrite decomposes into $\mathrm{M}_{23} \mathrm{C}_{6}$, $\sigma$-phase, and new austenite with increasing aging time as is noticed in micrographs [13].

The transformation of the $\delta$-ferrite has been known as the decomposition into two other phases [13].

$$
\begin{gathered}
\delta \rightleftarrows \mathrm{M}_{23} \mathrm{C}_{6}+\gamma \\
\delta \rightleftarrows \sigma+\gamma
\end{gathered}
$$

Figure 5 schematically shows the decomposition model from $\delta$-ferrite to austenite and $\sigma$-phase, as shown in Figure 4. Since the amount of chromium required for the formation of the $\sigma$-phase exceeds the amount of chromium contained in the $\delta$-ferrite, additional chromium must be supplied. This chromium is supplied from the $\delta$-ferrite zone so that austenite can be transformed simultaneously with the $\sigma$-phase. Thus, the new austenite is depleted of chromium compared to $\delta$-ferrite. Phase balance also 
requires splitting for a nickel. Both the $\sigma$-phase $/ \delta$-ferrite have low content. Therefore, the nickel content is reduced at the $\delta$-ferrite $\sigma$-phase interface for $\sigma$-phase formation. As shown in Figure 5 , the splitting of nickel and chromium is easily seen by diffusion along with the vacancy of austenite and $\delta$-ferrite interfaces. This interfacial diffusion promotes the migration of substituted (nickel, chromium) elements as compared to volume diffusion through the bulk phase at relatively low annealing temperatures.
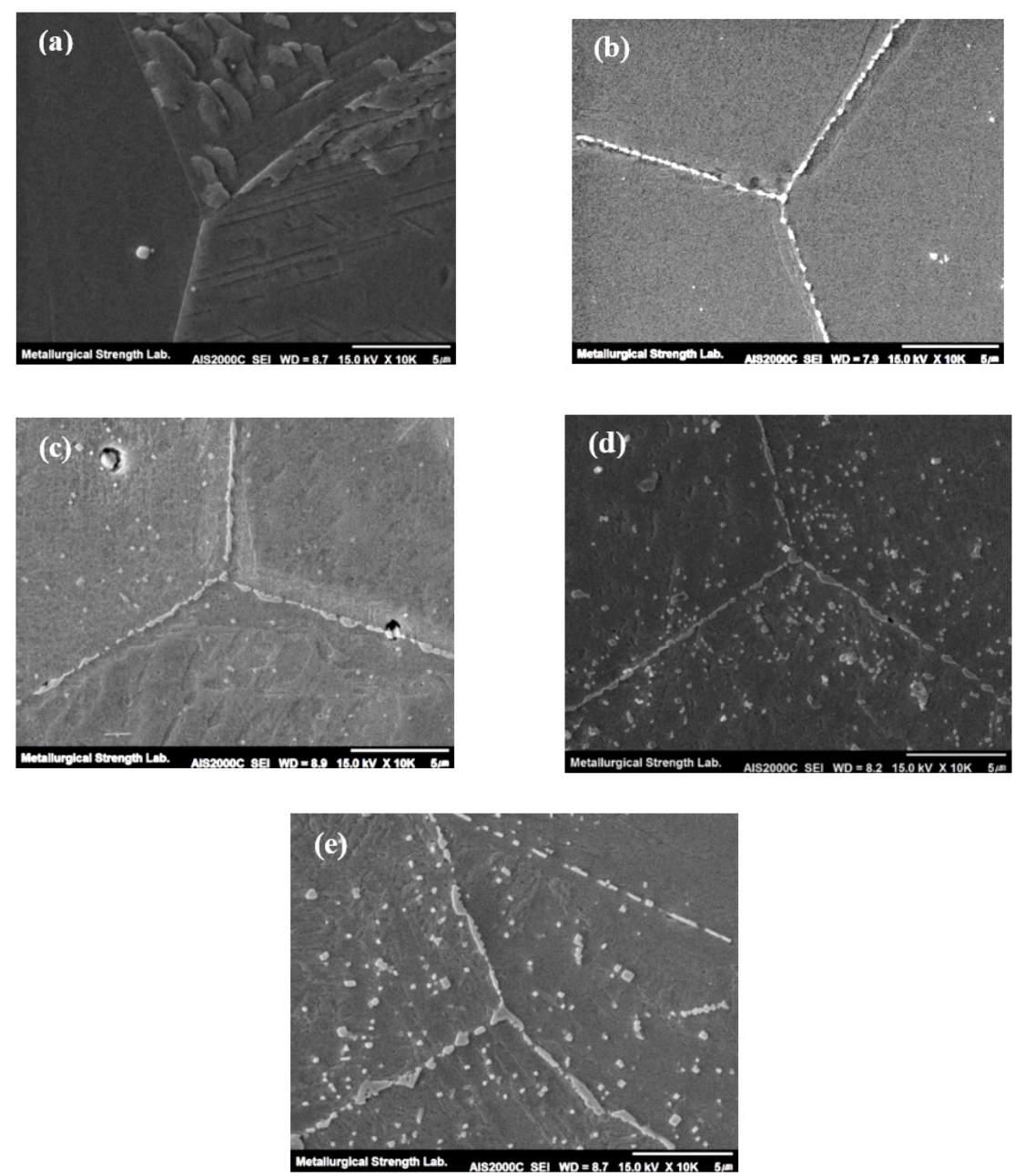

Figure 3. SEM micrographs of grain boundary precipitation; (a) 0 h, (b) 100 h, (c) 1000 h, (d) 5000 h, (e) $10,000 \mathrm{~h}$.

Figure 6 shows the result of the analysis of $\delta$-ferrite through EPMA. Figure 6a is a photograph showing the EPMA analysis result of the austenitized sample. The iron element content is higher in the austenitic matrix than in the $\delta$-ferrite. However, the chromium element content is higher in $\delta$-ferrite than in austenitic matrix due to the difference of $\mathrm{Cr}$ element content at each phase. Figure $6 \mathrm{~b}$ shows the EPMA analysis result of the 100-h aging specimen. As previously explained, the $\delta$-ferrite may be decomposed by heat treatment. In this stage, the $\delta$-ferrite already started the transformation into $\sigma$-phase, $\mathrm{M}_{23} \mathrm{C}_{6}$, and new $\gamma$-austenite. The chromium element content increased compared with $\delta$-ferrite and the iron element content increased within the center of $\delta$-ferrite interior due to the generation of new $\gamma$-austenite. This transformation is more progressive after 10,000 aging as shown in Figure 6c.

During the sensitization of austenitic AISI 304 steel, the intermetallic $\mathrm{M}_{23} \mathrm{C}_{6}$ carbides precipitated along grain boundaries and twin boundaries. Therefore, the $\mathrm{Cr}$ element depletion happens in the vicinity near these boundaries. In sensitized austenite steel, the grain boundaries and interfaces are thus more susceptible to martensitic transformation, sensitization induced martensite transformation. 
To analyze the sensitization induced martensite with long-term aging, $\mathrm{X}$-ray diffraction, ferrite scope, and magnetic force microscopy (MFM) were analyzed.
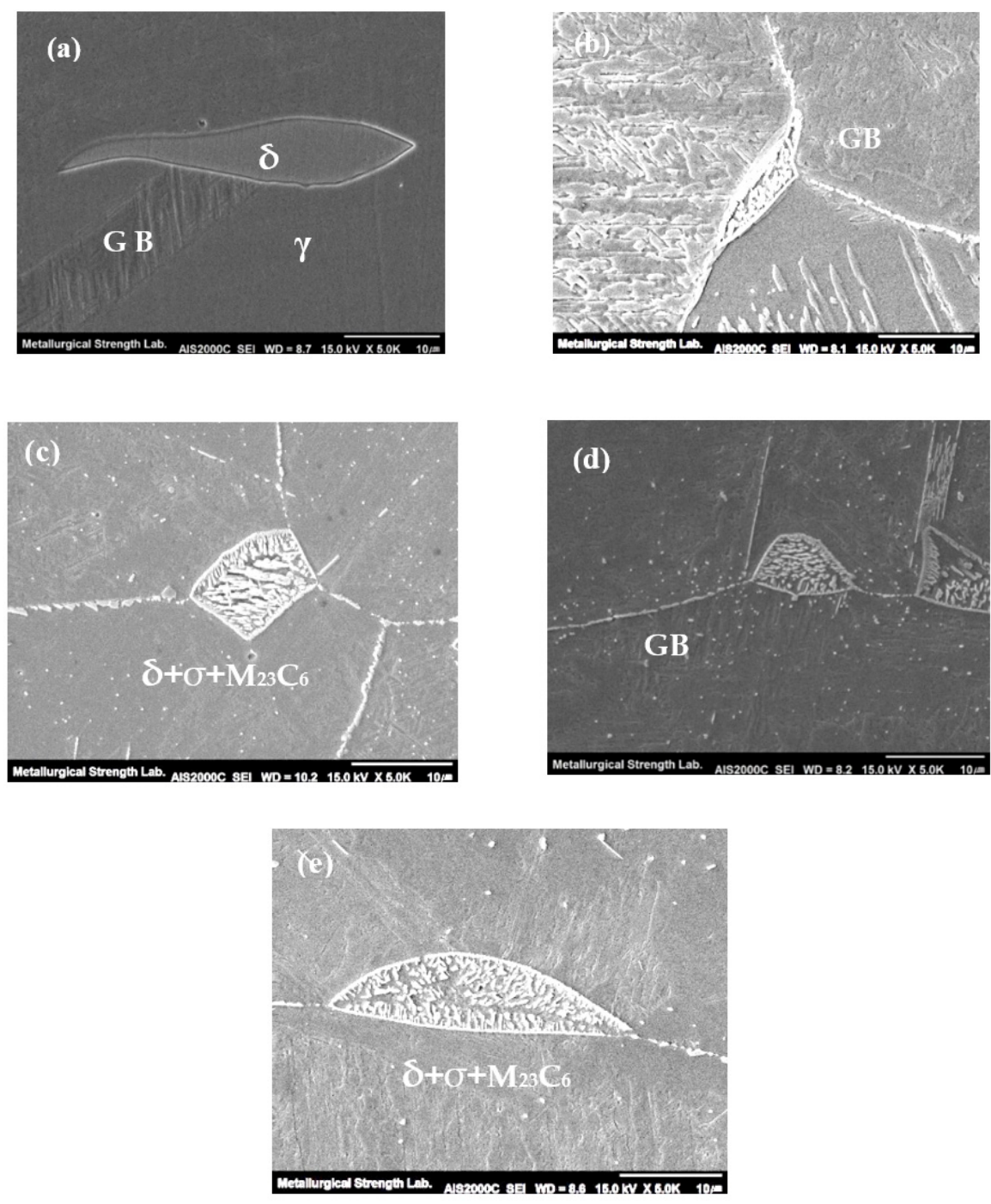

Figure 4. SEM micrographs of delta ferrite; (a) 0 h, (b) 100 h, (c) 1000 h, (d) $5000 \mathrm{~h}$, (e) 10,000 h.

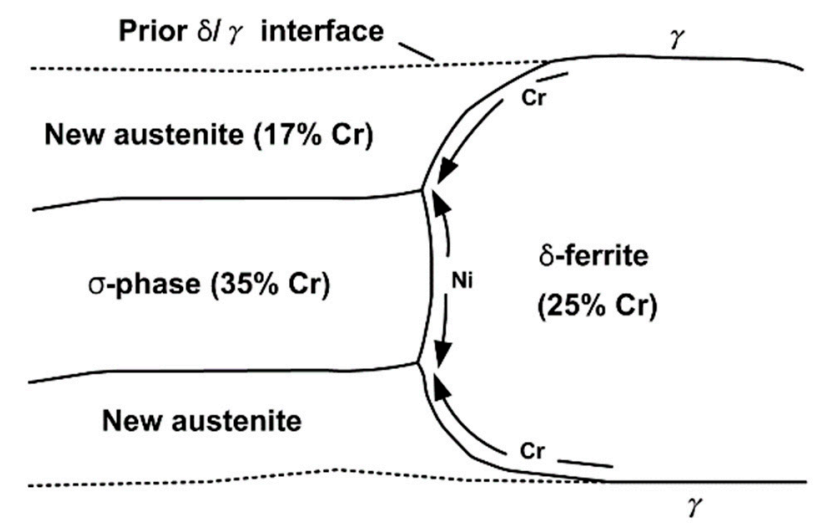

Figure 5. Schematic illustration of the transformation mechanism for delta-ferrite to sigma plus austenite reaction [13]. 

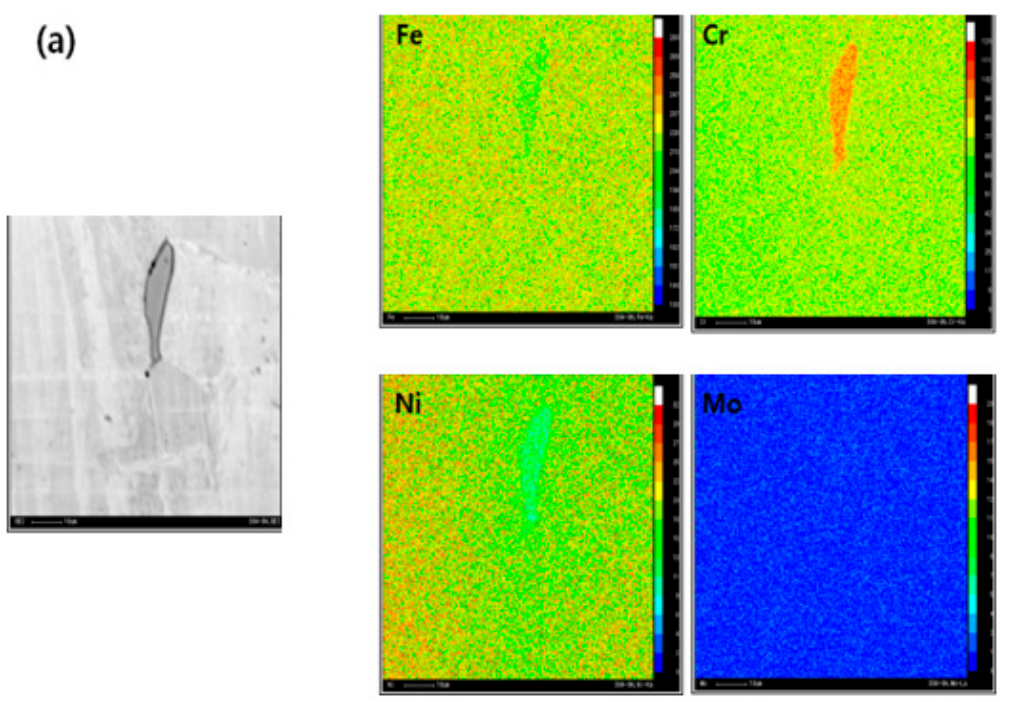

(b)
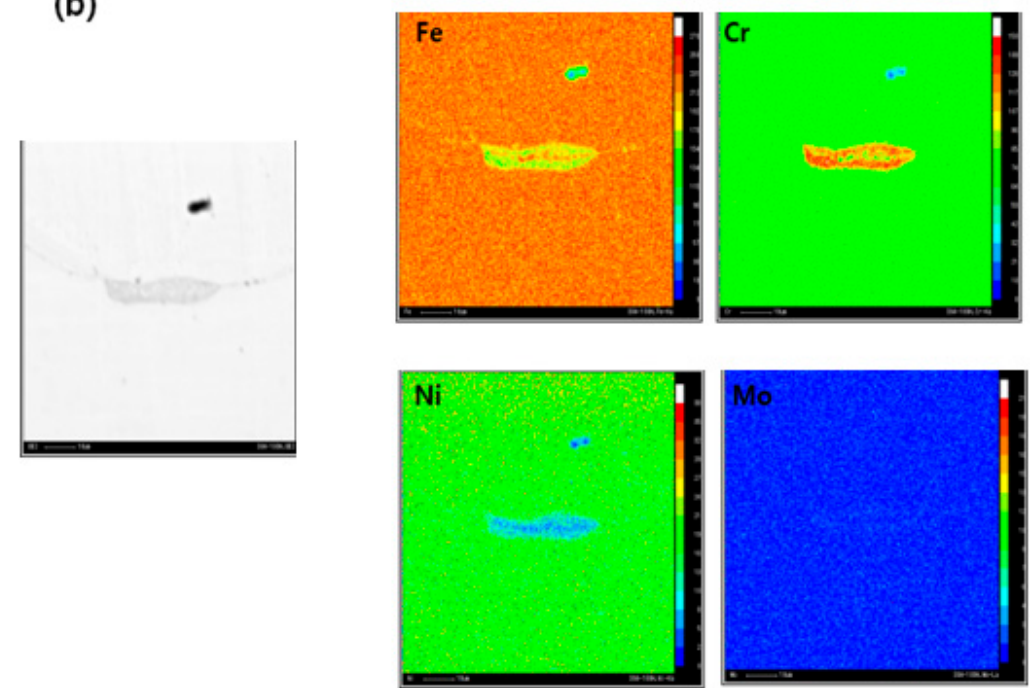

(c)
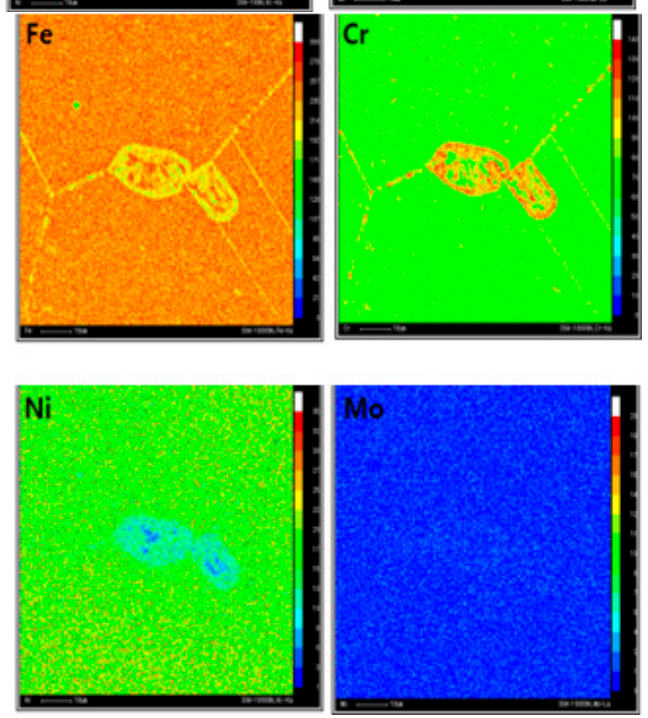

Figure 6. The EPMA elemental mapping of AISI 304 at each long-term aging time; (a) $0 \mathrm{~h}$, (b) $100 \mathrm{~h}$, (c) $10,000 \mathrm{~h}$.

Figure 7a shows the results of X-ray diffraction analysis. As already observed by the optical microscope and the secondary electron microscope, $\mathrm{X}$-ray diffraction analysis showed that the peak of 
$\delta$ - $\alpha^{\prime}$ increased as the heat treatment time increased due to the effects of $\delta$-ferrite and $\alpha$ '-martensite transformation. Figure $7 \mathrm{~b}$ shows the result of ferrite scope measurement. From these results, the ferrite fraction seemed to increase with increasing heat treatment time. However, as already observed through optical microscopy and scanning electron microscopy, the $\delta$-ferrite is decomposed into $\sigma$-phase, $\mathrm{M}_{23} \mathrm{C}_{6}$, and new $\gamma$-austenite with increasing heat treatment time. Since only $\delta$-ferrite is usually a magnetic phase of the austenitized sample, it can be analyzed by magnetic force microscopy to evaluate magnetic properties.

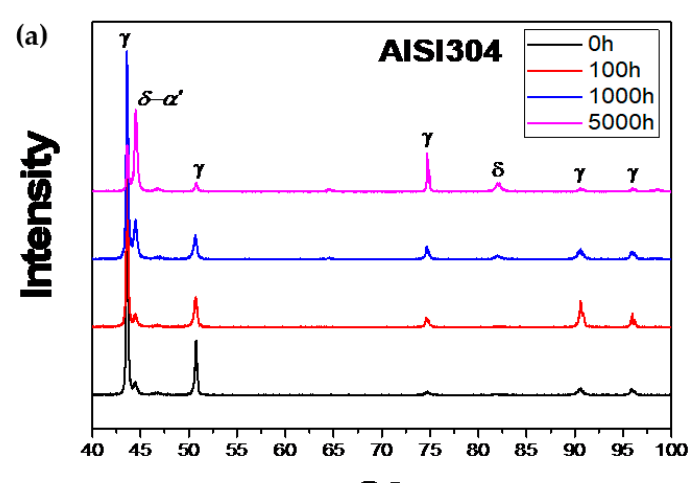

\section{0}

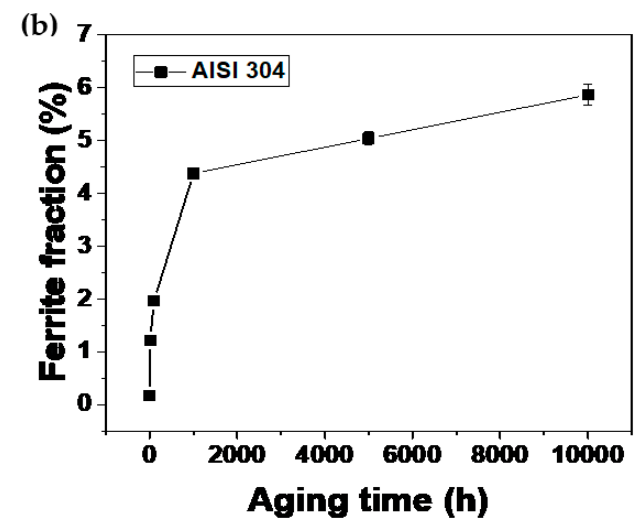

Figure 7. Variation in delta-ferrite with long-term aging of AISI 304; (a) XRD patterns and (b) ferrite fraction.

Takaya et al. observed the formation of martensite around grain boundaries through magnetic force microscopy [14]. Figure 8 shows the MFM micrographs of test specimens of 0, 5000, and 10,000 h. In this experiment, it is hard to observe the magnetic domain at $0 \mathrm{~h}$, but the magnetic domain was developed at $1000 \mathrm{~h}$. This magnetic domain can be observed near the grain boundary after $5000 \mathrm{~h}$ and $10,000 \mathrm{~h}$ heat treatment due to the generation of sensitization induced martensite transformation. In this study, the peak increases in the X-ray diffraction analysis and the increase of Ferrites cope reading mean the sensitization induced martensite had indeed been induced. 

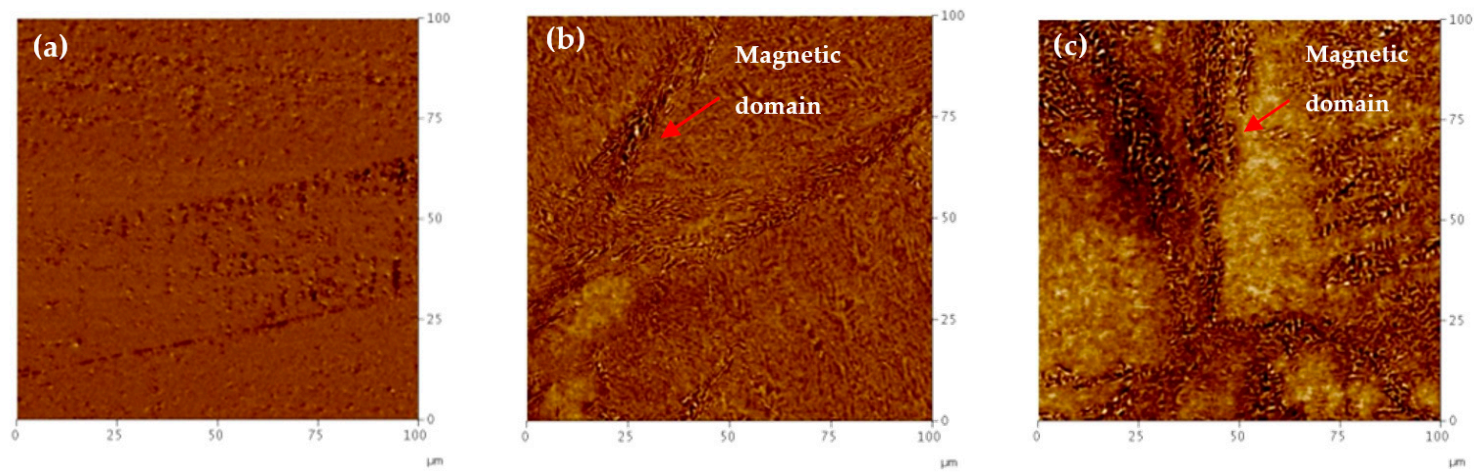

Figure 8. MFM micrographs at each long-term aging time; (a) 0 h, (b) $5000 \mathrm{~h}$, (c) 10,000 h.

\subsection{Corrosion Properties}

The electrochemical polarization test was conducted and extracted the corrosion potential ( $\left.\mathrm{E}_{\mathrm{corr}}\right)$ and corrosion current $\left(\mathrm{I}_{\mathrm{corr}}\right)$ for the polarization curves using the Tafel extrapolation method, as shown in Figure 9 and Table 2. The corrosion potential of austenitized specimen exhibited $-293 \mathrm{mV}$, and it is slightly increased for $100 \mathrm{~h}$ aging to $-238 \mathrm{mV}$. Additionally, for $1000 \mathrm{~h}$ of aging, the corrosion potential shows the minimum value of $-405 \mathrm{mV}$. The aging process promotes the active dissolution of test samples due to the generation of grain boundary carbides, which is the metastable intermetallic $\mathrm{M}_{23} \mathrm{C}_{6}$. Next, the corrosion potential increased to $-308 \mathrm{mV}$ for $5000 \mathrm{~h}$ aging and $-231 \mathrm{mV}$ for $10,000 \mathrm{~h}$ aging, respectively. Despite the difference in corrosion potential during long-term aging, the corrosion current density consistently increased with aging time. The corrosion current density is a significant value, which is closely related to the corrosion resistance more than the corrosion potential [15].

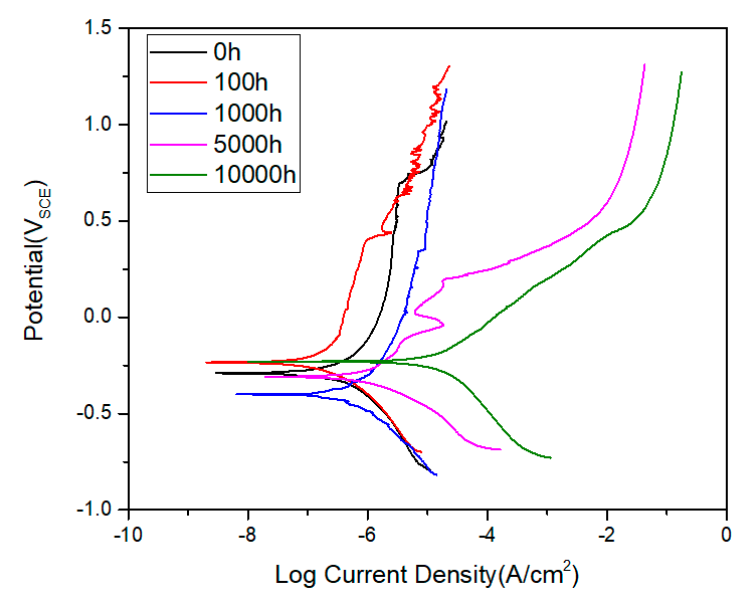

Figure 9. Polarization curve of long-term aging of AISI 304.

Table 2. The average value of current density and corrosion potential of long-term aging of AISI 304.

\begin{tabular}{ccc}
\hline Aging Time & Icorr $\left[\boldsymbol{\mu A} / \mathbf{c m}^{\mathbf{2}}\right]$ & Ecorr $[\mathbf{m V}]$ \\
\hline $0 \mathrm{~h}$ & 0.04 & -293 \\
$100 \mathrm{~h}$ & 0.04 & -238 \\
$1000 \mathrm{~h}$ & 0.09 & -405 \\
$5000 \mathrm{~h}$ & 0.473 & -308 \\
$10,000 \mathrm{~h}$ & 5.832 & -231 \\
\hline
\end{tabular}

Because it is directly proportional to the corrosion rate based on Faraday's law, the corrosion current density may be considered to estimate the corrosion behavior of long-term aging samples. The corrosion current density of the austenitized specimen exhibited a minimum value of $0.04 \mu \mathrm{A} / \mathrm{cm}^{2}$, 
and it is the same value with $100 \mathrm{~h}$ aging due to the not enough sensitization. Then, for $1000 \mathrm{~h}$ aging, it increased to $0.09 \mu \mathrm{A} / \mathrm{cm}^{2}$ and up to $5.8 \mu \mathrm{A} / \mathrm{cm}^{2}$ for $10,000 \mathrm{~h}$ aging. During the polarization test, the oxidation on the surface of the test specimen takes place when the cathodic scan ends and the anodic scan starts. The oxide film starts to form very slowly, and when the surface of metal exposed to the test is completely covered, the corrosion current becomes independent of potential. In general, when the material is lower, it means that it is easier for the material to lose its electrochemical reactivity (i.e., passivate current density, $\mathrm{I}_{\text {pass }}$ ) [16,17]. Easier passivation was observed until $1000 \mathrm{~h}$ aging, then it decreased a lot after $5000 \mathrm{~h}$ aging. As for pitting resistance, it appears but not clearly with increasing aging time. The highest pitting resistance was exhibited by the austenitized specimen having the highest pitting potential due to the absence of carbides and non-sensitization.

Diffusion along the grain boundary is sufficiently rapid and generates intermetallic phases near grain boundaries. The metastable intermetallic $\mathrm{Cr}$-rich phase, $\mathrm{M}_{23} \mathrm{C}_{6}$ carbides, are responsible for $\mathrm{Cr}$ depletion in the vicinity of the $\gamma / \gamma$ grain boundary interface and inside the ferrite phases [18]. This $\mathrm{Cr}$ depletion promotes the sensitization near the grain boundary and increases the current density with long-term aging. This phenomenon is dominant after $5000 \mathrm{~h}$ aging due to the formation of $\mathrm{Cr}$ rich carbides within gran interior, as previously shown in Figure 5. Therefore, the current density increased abruptly and resulted in a decrease in corrosion resistance. This $\mathrm{Cr}$ depletion is directly related to the generation of $\mathrm{M}_{23} \mathrm{C}_{6}$ carbides. Therefore, we should also consider the size and distribution of carbides during long-term aging when we evaluate the effect of precipitates on the corrosion resistance. We need to evaluate quantitatively the $\mathrm{Cr}$ depletion, size, and distribution of carbides for further research to investigate the influence of carbide on the corrosion resistance. In addition to the $\mathrm{Cr}$ depletion near the grain boundary, the ferrite islands along the grain boundary decomposed into $\sigma$-phase. For the formation of $\sigma$-phase, additional $\mathrm{Cr}$ must be supplied from ferrite and $\gamma$-austenitic matrix. Therefore, in the vicinity of $\gamma / \delta$ interface, the $\mathrm{Cr}$ depletion may be accelerated, causing also decrease in corrosion resistance with long-term aging. As a concluding result of the polarization test, the corrosion resistance of AISI 304 stainless steel subjected to long-term thermal aging decreases with aging time. The microstructural analysis results well support this result.

\section{Conclusions}

The effect of long-term aging of austenitic 304 steel on electrochemical corrosion characteristics has been investigated at a temperature of $700{ }^{\circ} \mathrm{C}$ for up to $10,000 \mathrm{~h}$. The following conclusions were drawn:

1. As the aging progresses for a long time, the metastable intermetallic $\mathrm{M}_{23} \mathrm{C}_{6}$ carbides generated in the vicinity of $\gamma / \gamma$ grain boundaries and coarsened with aging time. In addition to the grain boundary, the intermetallic phases also generated within the grain interior.

2. The $\delta$-ferrite decomposed into $\sigma$-phase, and $\mathrm{M}_{23} \mathrm{C}_{6}$ carbide with an aging time increase. This dissolution of $\delta$-ferrite was mainly attributed to the excess $\mathrm{Cr}$ depletion in the $\delta$-ferrite and $\gamma / \delta$ interface resulting from the $\mathrm{Cr}$ carbide precipitation.

3. The $\delta$-ferrite phase can be decomposed into $\sigma$-phase and $\mathrm{M}_{23} \mathrm{C}_{6}$ carbide in austenitic stainless steels, but the X-ray diffraction analysis showed an increased ferrite peak. It may be due to chromium depletion due to prolonged degradation and sensitization-induced martensite near the grain boundaries.

4. As the aging time increased, the current density increased, but the corrosion potential of the austenitized specimen exhibited a minimum value of $0.04 \mu \mathrm{A} / \mathrm{cm}^{2}$ due to the not enough sensitization. Easier passivation was observed until $1000 \mathrm{~h}$ aging, and the highest pitting resistance was exhibited by the austenitized specimen due to the absence of carbides. 
Author Contributions: C.H., S.A., and M.K. carried out the experiment. C.H. wrote the manuscript with support from S.A. and M.K. C.K. conceived the original idea and supervised the project.

Funding: This research was supported by the National Research Foundation of Korea (NRF) funded by the Ministry of Education (No. 2017R1D1A3B03028681).

Conflicts of Interest: The authors declare no conflict of interest.

\section{References}

1. Stoter, L.P. Thermal ageing effects in AISI type 316 stainless steel. J. Mater. Sci. 1981, 16, 1039-1051. [CrossRef]

2. Goyal, S.; Sandhya, R.; Valsan, M.; Bhanusankararao, K. The effect of thermal ageing on low cycle fatigue behaviour of 316 stainless steel welds. Int. J. Fatigue 2009, 31, 447-454. [CrossRef]

3. Jayakumar, T.; Mathew, M.D.; Laha, K. High Temperature Materials for Nuclear Fast Fission and Fusion Reactors and Advanced Fossil Power Plants. Procedia Eng. 2013, 55, 259-270. [CrossRef]

4. Takeuchi, T.; Kakubo, Y.; Matsukawa, Y.; Nozawa, Y.; Toyama, T.; Nagai, Y.; Nishiyama, Y.; Katsuyama, J.; Yamaguchi, Y.; Onizawa, K.; et al. Effects of thermal aging on microstructure and hardness of stainless steel weld-overlay claddings of nuclear reactor pressure vessels. J. Nucl. Mater. 2014, 452, 235-240. [CrossRef]

5. Vach, M.; Kuníková, T.; Dománková, M.; Ševc, P.; Čaplovič, L'.; Gogola, P.; Janovec, J. Evolution of secondary phases in austenitic stainless steels during long-term exposures at 600,650 and $800{ }^{\circ} \mathrm{C}$. Mater. Charact. 2008, 59, 1792-1798. [CrossRef]

6. Wright, I.S. Symposium on Coronary Heart Disease: The Use of Anticoagulants in Coronary Heart Disease Progress and Problems: 1960. Circulation 1960, 22, 608-618. [CrossRef] [PubMed]

7. Tekin, A.; Martin, J.W.; Senior, B.A. Grain boundary sensitization and desensitization during the ageing of 316L(N) austenitic stainless steels. J. Mater. Sci. 1991, 26, 2458-2466. [CrossRef]

8. Rhouma, A.B.; Amadou, T.; Sidhome, H.; Braham, C. Correlation between microstructure and intergranular corrosion behavior of low delta-ferrite content AISI 316L aged in the range 550-700 ${ }^{\circ} \mathrm{C}$. J. Alloys Compd. 2017, 708, 871-886. [CrossRef]

9. Dippenaar, R.J.; Phelan, D.J. Delta-ferrite recovery structures in low-carbon steels. Metall. Mater. Trans. B 2003, 34, 495-501. [CrossRef]

10. Gigovic-Gekic, A.; Oruc, M.; Muhamedagic, S. Effect of the delta-ferrite content on the tensile properties in Nitronic 60 steel at room temperature and $750{ }^{\circ} \mathrm{C}$. Mater. Tehnol. 2012, 46, 519-523.

11. Lo, K.H.; Zeng, D.; Kwok, C.T. Effects of sensitisation-induced martensitic transformation on the tensile behaviour of 304 austenitic stainless steel. Mater. Sci. Eng. A 2011, 528, 1003-1007. [CrossRef]

12. Park, S.H.C.; Sato, Y.S.; Kokawa, H.; Okamoto, K.; Hirano, S.; Inagaki, M. Corrosion resistance of friction stir welded 304 stainless steel. Scr. Mater. 2004, 51, 101-105. [CrossRef]

13. Song, R.; Xiang, J.; Hou, D. Characteristics of Mechanical Properties and Microstructure for 316L Austenitic Stainless Steel. J. Iron Steel Res. Int. 2011, 18, 53-59. [CrossRef]

14. Takaya, S.; Suzuki, T.; Matsumoto, Y.; Demachi, K.; Uesaka, M. Estimation of stress corrosion cracking sensitivity of type 304 stainless steel by magnetic force microscope. J. Nucl. Mater. 2004, 327, 19-26. [CrossRef]

15. Zhang, X.G. Corrosion Potential and Corrosion Current. In Corrosion and Electrochemistry of Zinc; Springer: Boston, MA, USA, 1996; pp. 125-156.

16. Zhang, G.A.; Cheng, Y.F. Micro-electrochemical characterization and Mott-Schottky analysis of corrosion of welded X70 pipeline steel in carbonate/bicarbonate solution. Electrochim. Acta 2009, 55, 316-324. [CrossRef]

17. Li, B.; Huan, Y.; Zhang, W. Passivation and Corrosion Behavior of P355 Carbon Steel in Simulated Concrete Pore Solution at $\mathrm{pH} 12.5$ to 14. Int. J. Electrochem. Sci. 2017, 12, 10402-10420. [CrossRef]

18. Warren, A.D.; Griffiths, I.J.; Flewitt, P.E.J. Precipitation within localised chromium-enriched regions in a Type 316H austenitic stainless steel. J. Mater. Sci. 2018, 53, 6183-6197. [CrossRef]

(C) 2019 by the authors. Licensee MDPI, Basel, Switzerland. This article is an open access article distributed under the terms and conditions of the Creative Commons Attribution (CC BY) license (http://creativecommons.org/licenses/by/4.0/). 